\title{
Institutional Perspectives on Faculty Development for Digital Education in Canada
}

Perspectives institutionnelles sur le développement du corps professoral pour l'éducation numérique au Canada

Charlene A. VanLeeuwen, Royal Roads University

George Veletsianos, Royal Roads University

Olga Belikov, Simon Fraser University

Nicole Johnson, Canadian Digital Learning Research Association

\begin{abstract}
As digital education at the postsecondary level continues to grow, robust professional development that prepares faculty to teach in online and blended settings is necessary. In this study, we analyzed openended comments from the Canadian Digital Learning Research Association's annual survey of Canadian postsecondary institutions (2017-2019) to deepen our understanding of faculty training and support for digital education as articulated by higher education institutions. We found that: a) digital education orientation or on-boarding processes for faculty vary widely; b) institutions employ an extensive array of professional development practices for digital education; c) institutions report culture change, work security, and unclear expectations as challenges in providing digital education training and support; and d) institutions articulate aspirations and hopes around professional development investments in order to build digital education capacity. These findings have significant implications for research and practice, which we describe in this article.
\end{abstract}

Keywords: professional development, online learning, Canada, faculty development; faculty training

\section{Résumé}

Alors que l'éducation numérique au niveau post-secondaire continue de se développer, un solide développement professionnel qui prépare les professeurs à enseigner en ligne et dans des environnements hybrides est nécessaire. Dans cette étude, nous avons analysé les commentaires ouverts de l'enquête annuelle de l'Association Canadienne de Recherche sur la Formation en Ligne sur les établissements d'enseignement supérieur canadiens (2017-2019) afin d'approfondir notre compréhension de la formation des professeurs et du soutien à l'éducation numérique tel qu'il est formulé par les 
établissements d'enseignement supérieur. Nous avons constaté que les processus d'orientation ou d'intégration des professeurs à l'éducation numérique varient considérablement ; 1) l'orientation de l'éducation numérique ou les processus d'intégration des professeurs varient considérablement; 2) les établissements emploient un large éventail de pratiques de développement professionnel pour l'éducation numérique ; 3) les établissements signalent le changement de culture, de la sécurité au travail et des attentes floues comme étant des défis à relever pour fournir une formation et un soutien à l'éducation numérique ; et 4) les établissements articulent leurs aspirations et leurs espoirs autour des investissements dans le développement professionnel afin de renforcer les capacités en matière d'éducation numérique. Ces résultats ont des implications importantes pour la recherche et la pratique, et nous les décrivons dans cet article.

Mots clés : développement professionnel, apprentissage en ligne, Canada, développement du corps professoral ; formation du corps professoral

\section{Introduction}

In the face of the COVID-19 pandemic, where postsecondary institutions in Canada rapidly transitioned to remote teaching and learning, we see a renewed and heightened interest in professional development (PD) to prepare and support faculty teaching in digital education contexts. Digital education refers to teaching and learning activities which make use of digital technology as part of inperson, blended, and fully online learning contexts. The large-scale shift to remote forms of teaching and learning reflects an extraordinary time in higher education. However, an investigation of the perspectives of higher education stakeholders in Canada around faculty PD may yield insights that can inform efforts to support future course delivery efforts. To address the numerous changes that the postsecondary sector is facing-not just from COVID-19 but also demographic, technological, and societal changes-faculty need more than content expertise. They also need to understand various other aspects of teaching and learning, including how learning happens, what forms of assessment are amenable to online and blended formats, as well as understand the strengths and limitations of specific teaching methods and modalities. It is therefore important that institutions provide relevant and robust training for faculty, graduate students, and administrators in order to help them make evidence-based decisions with respect to digital education efforts (Brown et al., 2020; Carter et al., 2014).

Canadian data about faculty orientation, on-boarding for digital education, and on-going professional development are scarce. One source of data is the annual pan-Canadian survey developed by the Canadian Digital Learning Research Association/Association Canadienne de Recherche sur la Formation en Ligne (CDLRA) which focuses on issues pertaining to digital education in Canadian postsecondary education (Bates et al., 2017; Donovan et al., 2018; Johnson, 2019). Survey results have been shared through annual reports with detailed analysis of quantitative data. While respondents were asked open-ended questions, the reports largely rely on quantitative findings, using qualitative data only sporadically to illustrate quantitative findings. 
To further scholarly understanding of digital education in Canada, we conducted a systematic analysis of the narrative comments in these surveys. In this study we report our analysis of the data from the open-ended questions of the 2017-2019 CDLRA surveys that focus on institutional perspectives regarding faculty training and support for digital education in Canada. Our rationale for conducting this analysis, the context for this study, and the methods are outlined below. We then present the themes identified in our findings, followed by a discussion of these results.

\section{Rationale and Literature Review}

Most faculty would benefit from pedagogical training that supports them in fostering student learning (Christensen Hughes \& Mighty, 2010). Here, we outline literature related to institutional perspectives associated with PD, training, and support for digital education for postsecondary faculty in Canada. As we examine key aspects of the literature, we note that there is substantial variation in terminology and that several terms are used interchangeably in the faculty development literature (Inamorato dos Santos et al., 2019). For the purpose of this paper, we view faculty PD, training, and support as structured learning opportunities aimed at enhancing skills, knowledge, attitudes, and practices (Darling-Hammond, 2017; Kneale et al., 2016).

Many studies of higher education faculty note the importance of pedagogical training for new instructors (e.g., Carter \& Brockerhoff-Macdonald, 2011; Johnston, 1997; Miller, 1997; Ödalen et al., 2019). The literature also highlights a debate around whether training for faculty teaching in Canadian colleges, polytechnics, and universities ought to be mandatory (Austin \& Sorcinelli, 2013; Christensen Hughes \& Mighty, 2010; Pettigrew, 2011; Rodgers, Christie, \& Wideman, 2014). Both the European Commission and the Organisation for Economic Co-operation and Development have published reports which note the importance of fostering quality teaching, not only at the individual and program level, but also through institution-wide initiatives (Hénard, 2009; Hénard \& Roseveare, 2012; Inamorato dos Santos et al., 2019). In addition, the Higher Education Quality Council of Ontario noted the important role faculty training plays in ensuring high quality education for postsecondary students (Gregory \& Cusson, 2013; Miles \& Polovina-Vukovic, 2012). Innovations in faculty development can be key strategic levers for institutions to ensure quality, as well as mechanisms to support innovation and change (Austin \& Sorcinelli, 2013; Carter et al., 2014; Inamorato dos Santos et al., 2019; Randall et al., 2013).

There have been continued calls for higher education institutions (HEIs) to provide opportunities for faculty to develop pedagogical and technical expertise in digital education (e.g., Bates, 2016, 2019a, 2019b; Brown et al., 2020; Inamorato dos Santos et al., 2019). Workshops, courses, or certificate programs are offered for faculty to explore teaching strategies and modalities, engage with educational research literature, and reflect critically on various approaches to teaching (Randall et al., 2013); however, these often exclude short term contract faculty in adjunct and sessional appointments and graduate students (Austin \& Sorcinelli, 2013). Further, the professional development needs of faculty vary depending on subject area, the instructor's prior experience and career stage, as well as course modality. It may therefore be worthwhile to provide new challenges and fresh opportunities in 
pedagogical practice for both highly experienced faculty members and those new to the profession (Austin \& Sorcinelli, 2013).

\section{Research Context}

The higher education context in Canada includes 10 provincial and three territorial governments sharing responsibility for education as part of a devolved governance system. According to the CDLRA, there are 234 publicly-funded higher education institutions at the time of writing-which include five distinct types of institutions (universities, polytechnics, colleges, collèges d'enseignement général et professionnel, and private subsidized colleges)-there are no pan-Canadian policies or systems bringing them together. Reports from the three pan-Canadian surveys conducted by the CDLRA between 2017 to 2019 reveal the evolving definitions of digital education in Canada, challenges in tracking enrolment data, range of educational technologies used, and importance of digital education to the future of responding institutions (Bates et al., 2017; Donovan et al., 2018; Johnson, 2019). Each year, HEIs reported continued growth across all course modalities from fully online courses to blended/hybrid offerings. The reports also drew attention to innovative developments with alternative credentials, paradoxical findings related to institutions' long-term plans for digital education, adoption of open educational resources and practices, and emerging topics surrounding faculty training for digital education initiatives. Our earlier investigation of the CDLRA survey comments identified six themes, some of which relate to faculty PD, training, and support for digital education (Veletsianos et al., 2020). For example, institutions' reporting of their innovations pertaining to digital course development and teaching is inextricably linked to faculty professional development and support.

The 2017, 2018, and 2019 CDLRA reports included some mention of faculty PD. These reports identified inadequate faculty training for digital education as a key barrier to the growth of online teaching, even though questions in the 2017 survey did not directly ask institutions about PD for faculty involved in digital education (Bates et al., 2017). The 2018 and 2019 survey questions were revised to ask about PD for online teaching. In 2018, institutions were asked about the best ways to provide faculty with training/pedagogical knowledge; however, results were not included in the report. In 2019, there was a focus on orientation and PD for faculty prior to teaching their first online course. Findings showed that orientation and on-going training for online teaching is rarely mandated by HEIs. More detailed results revealed that $29 \%$ of responding institutions require faculty to complete training prior to teaching online, over half (58\%) reported offering voluntary orientation or training, and only 12 institutions out of the 164 responding institutions indicated no PD was offered before faculty teach online.

\section{Objectives and Research Question}

The objective of this study was to provide a richer and multi-year view of PD, training, and support for digital education available to faculty at Canadian postsecondary institutions. We achieved this objective by conducting a systematic analysis of narrative responses related to faculty PD, training, and support for digital education from the open-ended questions of the three pan-Canadian CDLRA 
surveys from 2017-2019. The research question we asked was: How do postsecondary institutions describe faculty training and support for digital education in Canada?

\section{Methods}

At the time of writing, the CDLRA had conducted its annual National Survey of Online and Digital Learning in 2017, 2018, and 2019. The survey targeted all publicly-funded postsecondary institutions in Canada and was sent between April and August via email to institutional leaders at every institution on the survey roster. Invitations to participate were sent to 203 institutions in 2017 with a $69 \%$ response rate, and 234 each year in 2018-2019 with response rates of $80 \%$ and $70 \%$ respectively. While one survey was sent to each institution, in many cases, the survey results for an institution reflect the responses of multiple individuals. This is due to the fact that the breadth and depth of questions cannot typically be answered by a single individual. The surveys included 10 to 11 sections, each with an optional open-ended comment. Respondents were invited to share additional comments related to each section as well as at the end of the survey. In many cases, respondents left one or more of the comments blank. In some instances survey respondents changed from year to year.

At the time of writing, upon request by third-party researchers, the CDLRA made available deidentified and anonymized data it collected for secondary use. Data for this study consisted of responses to the 36 open-ended comments in the CDLRA surveys (nine for 2017; 16 for 2018; and 11 for 2019). In total, the dataset consisted of 110,106 words (26,366 words for 2017; 61,977 for 2018; and 21,763 for 2019). Prior to analysis, comments written in French were translated into English using an Internetbased artificial intelligence translation service, and translations were examined and edited for accuracy, clarity, spelling, and completeness by one of the authors.

Data were analyzed through constant comparison of codes, identification of emergent themes, memo-writing about category and theme development, and iterative analysis (Glaser \& Strauss, 1967). Open coding began with two members of the research team independently coding the data using Dedoose, a qualitative analysis software. Through iterative discussions with the entire research team, broad categories with codes and sub-codes were identified and defined for each individual year of survey responses. Initial codes were refined and reduced to develop a codebook consisting of eight categories and 84 codes, representing the breadth and depth of the entire dataset, complete with definitions for each category and code (Creswell, 2014). To systematically analyze data for this publication, a further round of focused and selective coding (Charmaz, 2006) was conducted independently by the same two team members. Where appropriate, data excerpts were compared code by code to reach consensus between coders. Careful consideration was given to ensure rigor and trustworthiness of this study by following established processes for data analysis and reporting, including the presence of an audit trail and using sensitizing concepts to organize data and make decisions about the significance and importance of findings (Patton, 2015). In presenting findings for this study, themes and examples from the data were shared in ways that may be relevant to readers and allow them to determine the applicability of findings to their own contexts (Patton, 2015; Sandelowski, 2000). 
To help readers understand how data were interpreted, we sought to acknowledge our positionality (Freeman et al., 2007). All authors are interested in the use of technology in education and have experience with higher education teaching, learning, and research. The fourth author is employed by the Canadian Digital Learning Research Association and was the primary author for the 2019 CDLRA National Report.

\section{Findings}

We identified four themes that describe faculty training and support for digital education in Canada, as follows:

- Institutions employ an extensive array of PD practices for digital education

- Higher Education Institutions articulate aspirations and hopes around PD investments to build digital education capacity

- Culture change, work security, and unclear expectations identified as challenges in providing digital education training and support

- Digital education orientation or on-boarding processes for faculty vary widely

\section{Institutions Employ an Extensive Array of PD Practices for Digital Education}

The data from all three years of the surveys revealed rich information about the broad range of PD practices and modalities used by HEIs. For example, the 2018 survey specifically asked institutions to share comments about the best ways they provide faculty with training/pedagogical knowledge, while the 2019 survey focused on institutions' PD practices for new and experienced faculty prior to teaching online. Overall, 101 respondent comments elaborated on approaches to PD at their institution, rather than simply stating who was responsible for providing training and PD. Examples contrasting these two types of comments are as follows: "Ideally they [faculty] are provided one-to-one support for online course development -- we have a blend of centralized and faculty/department specific support" (Respondent 6, 2018) and "The Centre for Innovation in Teaching and Learning, as the main support unit for Teaching and Learning at our institution, has specific objectives and targets identified in relation to the development of online courses and programs" (Respondent 111, 2018). There were 30 comments which mentioned how digital education training and PD can have benefits which extend beyond the intended digital settings. Respondents noted that "generally, moving to a new and different modality leads one to think critically about teaching and learning strategies" (Respondent 91, 2018); which may help ". . . faculty move outside their comfort zone and explore possibilities that also have relevance in the traditional, face-to-face classroom” (Respondent 28, 2018). In addition, there were a small number of comments noting the benefits institutions have seen from providing timely training for digital initiatives; for example, “Although our instructors using Brightspace (the institution's Learning Management System) has gone from 137 to 1,314 in the last two years, support/helpdesk calls around Brightspace (the institution's Learning Management System) have not increased significantly. Therefore, showing the positive impact of providing adequate training to support software rollout" 
(Respondent 18, 2017). It was not clear whether these comments shared by respondents are anecdotal in nature or based on evidence from research or quality assurance evaluations from their institution.

Survey respondents shared the extensive variety of practices they employ to provide faculty PD, training, and support for digital education. These include training that can be undertaken independently by faculty members, one-to-one interactions with others such as instructional design professionals or peers, and group PD opportunities. Respondents such as this one acknowledge the need for flexibility in their PD approaches: "It would be best to have them learn through multiple ways such as training workshops/courses on online course development and facilitating online, seeing exemplar courses, peer mentorship, just-in-time support and resources, etc." (Respondent 125, 2018). Responding institutions shared many comments which spoke to the array of practices employed. Table 1 presents a synopsis of practices described.

Table 1

Digital Education, Professional Development, and Training Practices Employed by Canadian Postsecondary Institutions

\begin{tabular}{|c|c|}
\hline Practice & Description \\
\hline $\begin{array}{l}\text { Educational workshops } \\
\text { and meetings }\end{array}$ & $\begin{array}{l}\text { Workshops in a variety of formats such as train the trainer, } \\
\text { brown bag lunches, hands-on workshops in re-conceptualizing course } \\
\text { design, external/internal teaching showcases, symposia, etc., with training } \\
\text { targeted for specific digital modalities (online/blended/hybrid/hyflex) or } \\
\text { highlighting different pedagogical strategies for digital education. }\end{array}$ \\
\hline $\begin{array}{l}\text { Personalized individual } \\
\text { one-to-one training and } \\
\text { support }\end{array}$ & $\begin{array}{l}\text { Individual PD focused on instructional design/technical training } \\
\text { accompanied by just in time support throughout implementation. }\end{array}$ \\
\hline Exploratory practice & $\begin{array}{l}\text { Opportunities for faculty to experiment and practice with unfamiliar } \\
\text { technology tools or teaching strategies that best address the type of learning } \\
\text { experience they are trying to create prior to implementation in classes. }\end{array}$ \\
\hline $\begin{array}{l}\text { Participation in } \\
\text { exemplar online courses }\end{array}$ & $\begin{array}{l}\text { Provide online courses for faculty to experience digital education from the } \\
\text { viewpoint of a student; model courses for faculty to explore before teaching } \\
\text { in online settings. }\end{array}$ \\
\hline $\begin{array}{l}\text { Intensive course } \\
\text { redesign }\end{array}$ & $\begin{array}{l}\text { Redesign of course activities with wrap around instructional design and } \\
\text { technologist supports. }\end{array}$ \\
\hline Champions and mentors & $\begin{array}{l}\text { Experienced faculty champions with digital education knowledge and skills } \\
\text { who provide support and mentorship to colleagues and promote various } \\
\text { digital education initiatives on campus. }\end{array}$ \\
\hline
\end{tabular}




\begin{tabular}{ll}
\hline Practice & Description \\
\hline Community of practice & $\begin{array}{l}\text { Small groups of faculty which form together as a community of practice to } \\
\text { learn as a group, facilitate peer-to-peer networking, or raise the profile of } \\
\text { digital education; may include faculty peers, staff from a teaching and } \\
\text { learning centre, and a facilitator. }\end{array}$ \\
Reflective practice & $\begin{array}{l}\text { Encouraging faculty to think about what went well/not so well with digital } \\
\text { learning activities and what/where they could improve. Could be an } \\
\text { individual practice, a component of the activities for a community of } \\
\text { practice, or discussion within a mentoring partnership. }\end{array}$ \\
$\begin{array}{l}\text { Incentives (e.g., } \\
\text { financial, recognition, } \\
\text { release time) }\end{array}$ & $\begin{array}{l}\text { Various incentives available to faculty to attend training or develop digital } \\
\text { learning activities include release time, financial incentives, compensation } \\
\text { for attending training, recognition of excellence in digital education through } \\
\text { tenure and promotion processes, and awards. }\end{array}$ \\
$\begin{array}{l}\text { Investment in } \\
\text { scholarship of teaching } \\
\text { and learning initiatives } \\
\text { and research }\end{array}$ & $\begin{array}{l}\text { Systematic study of teaching and learning in digital education with public } \\
\text { sharing and review of such work to share innovations in curriculum } \\
\text { development and content delivery strategies. }\end{array}$ \\
\hline
\end{tabular}

\section{Higher Education Institutions Articulate Aspirations and Hopes Around PD Investments to Build Digital Education Capacity}

Based on comments from 61 respondents, two important strategies for changing negative stereotypes and promoting positive faculty attitudes around digital education are instructional design support and PD that allows faculty to learn about high quality outcomes that arise from well-designed digital education. One example that voices this idea comes from Respondent 176 who stated "Education, information, training. There are a lot of preconceptions about online courses. We must continue to demystify this modality and educate faculty" (2018). We noted responses across all years of the survey that looked forward to greater opportunities for faculty to "get to work with instructional designers" (Respondent 119, 2017). Respondents from HEIs also view continued investment and expansion of faculty PD, training, and support as an opportunity to build digital education capacity as evidenced by this comment: "We are continuing to expand and build on a diverse array of faculty development offerings focused on digital pedagogy, to support capacity-building and evidence-informed teaching practice" (Respondent 126, 2017). Finally, respondents noted the necessity for multi-level cultural changes on their campus for the success of digital education initiatives.

There are a number of elements needed to achieve this. The learning culture needs to expand to encompass online learning-which begins with acceptance by senior leaders. Online learning needs to be built into strategic, academic and business plans. Strong IT support is required and supports must be in place for online learners. In addition, the faculty and employees of colleges need to also adopt a practice of learning using online resources. (Respondent 206, 2018) 


\section{Culture Change, Work Security, and Unclear Expectations Identified as Challenges in Providing Digital Education PD, Training, and Support}

While HEIs shared a number of challenges and barriers related to faculty PD, training, and support, three challenges were reiterated by 59 respondents. These were related to culture change, work security, and unclear expectations. First, challenges around the development of PD that would complement the culture change needs of their institution, as well as training targeted towards a specific institutional culture were mentioned. For example, Respondent 190 (2018) alluded to the use of "change management strategies to educating faculty" and Respondent 55 stated,

A commitment to changing the organizational culture is the first step. Getting faculty to understand that this is the future state of the institution will facilitate buy in. Substantial training is critical for faculty. Some faculty will be extremely resistant to adopting this methodology and may not be the best for this type of teaching. (2018)

Second, work security concerns emerged as another challenge. Respondents noted the need to "ensure job security" (Respondent 59, 2018) and explained that "online needs to be non-threatening, i.e., fear of job loss" (Respondent 178, 2018). Multiple respondents expanded on concerns that faculty might have by sharing statements that address how institutions may approach this potential fear such as the following: ". . . reassure them about their role and by small steps make them aware of the advantages that digital can offer to facilitate their work ..." (Respondent 135, 2018). The third challenge that emerged in comments was related to institutional expectations for digital education. Respondents articulated the need for clear expectations related to digital education in statements where they noted a need for "A clear vision communicated by leadership about what the educational offerings of the institution are expected to look like and include, including a fully articulated plan/blended learning strategy" (Respondent 110, 2018).

\section{Digital Education Orientation or On-boarding Processes for Faculty Vary Widely}

Survey comments described PD experiences that extended beyond orientation for new faculty to include on-boarding processes for faculty at all career stages wanting to incorporate educational technology into their teaching. While most postsecondary institutions provide orientation sessions for new faculty, what is not clear is how HEIs across the country prepare instructors to use digital learning technologies in their classes. Respondents offered a few comments (three in 2017; 17 in 2018; and 17 in 2019) about faculty orientation for digital education in all years of the surveys. Most of these comments referred to pre-service digital education training for faculty, noting whether or not training was mandatory. Comments revealed varied practices ranging from compulsory to voluntary training prior to beginning teaching in an online environment, such as Respondent 63 who stated: "We have a variety of supports available but no formal mandated training" (2019). Situations where pre-service or orientation training may not be complete before faculty members start online teaching activities were also described in comments such as this one: "Professional development is mandatory, however this does not always occur prior to teaching online due to scheduling, last minute hires, etc.” (Respondent 5, 2019). 
Analysis of comments revealed mixed uptake described by some institutions where PD focused on technical and pedagogical aspects of digital education as available for new and experienced instructors. For instance, Respondent 10 wrote, "In our case, we offer training opportunities, but a significant portion of our faculty do not want to invest in this area" (2018); whereas Respondent 152 wrote, ". . . we have a professional development online course that is very popular among the faculty: over 160 faculty members have received recognition for completing this course" (2018). Respondents also specifically acknowledged the different needs of experienced faculty, who are looking to add elements of digital education into their face-to-face courses, adapt portions of an existing face-to-face course to a blended/hybrid modality, or create a new course using blended/hybrid or completely online modalities. Most respondents shared general descriptions of their PD offerings, similar to this example:

Appropriate supports and resources to make the transition to online teaching pleasant, rewarding and fulfilling. Provide templates, or eLearning staffing to prepare courses in a way that allows faculty to focus on subject matter and pedagogy and not solely on technology. Tiered faculty achievement recognition/reward system is being explored to recognize professional development. (Respondent 16, 2018)

Inequities related to PD opportunities, particularly for sessional or adjunct faculty at their institution, were mentioned by a handful of respondents. There were comments that make it clear that all faculty have access to PD for digital education, such as this one from Respondent 76 who stated, "Both full-time and part-time faculty are obligated to participate in professional instructional development at the outset of their career with the college. An orientation to teaching with technologies and to the college Learning Management System (LMS) is included in these programs" (2019). At the same time, there were comments which reveal inequitable access for some instructors, with PD "provided to full-time faculty, but not consistently available to sessional instructors" (Respondent 12, 2019). Another perspective shared by Respondent 64 noted that "staff work with some faculty to develop their online course so they may get extensively trained. Other faculty do not and so may not get any individualized training" (2019).

\section{Discussion}

These findings have significant implications for Canadian HEIs. Below we discuss a variety of ways that researchers and practitioners may use these results.

\section{Faculty Orientation, On-boarding, and Ongoing PD to Ensure Readiness and Capacity for Digital Education}

Diverse approaches for faculty orientation, on-boarding, and ongoing PD for digital education demonstrates a wide range of innovative opportunities; however, at some institutions PD for digital education is inconsistent, which can leave faculty less prepared for teaching in digital spaces. Our findings indicate that some institutions have an assortment of well-developed and robust systems in place for faculty orientation, on-going PD, training, and support for digital education; more 
significantly, and of concern, are institutions where faculty are expected or asked to teach online with little or no techno-pedagogical training and support.

HEIs can take steps to ensure they offer the requisite pre-service preparation, starting with reflection on the pedagogical, digital literacy, and technological knowledge and skills needed by new faculty. Various scholars have called for pre-service preparation for university faculty for face-to face and online teaching through mandatory courses, micro credentials, or other techno-pedagogical workshops or training for some time (e.g., Austin \& Sorcinelli, 2013; Bates 2016, 2019a, 2019b; Veletsianos, 2020b). These scholars have also described aspects of university teaching and learning that pre-service formation should ideally focus on, including components associated with use of educational technology, hybrid/blended, and online education.

At the same time, careful consideration should be given to PD to prepare experienced faculty to teach in digital spaces as their situational needs and expectations may differ from new faculty (Cooney, 2019). Ongoing PD focused on both technology and pedagogy with adequate support needs to be a priority, in keeping with the core goals for faculty development related to teaching which include fostering exploration, renewal, and change (Carter et al., 2014; Sorcinelli et al., 2006). Some faculty training needs are institution-specific (e.g., how to use the LMS; how to use the institution's videoconferencing system), while others have broad applicability across institutions (e.g., developing learning objectives which lead to meaningful assignments and authentic assessment in online settings). It is in these non-institution-specific areas where there is potential for PD opportunities related to digital pedagogy that may be shared among institutions, ensuring adequate orientation and ongoing training for faculty. Collaborative PD models can offer consistent, cost-effective options that can be one-time shared offerings or ongoing partnerships (Inamorato dos Santos et al., 2019). Examples of such collaboration include small groups of Canadian institutions who share faculty development, such as the case with the Maple League Universities (Wells et al., 2019) or openly licensed, fully online professional learning programs for foundational digital literacy skills such as those offered by BCcampus (n.d.) and @eCampusOntario (n.d.). Maintaining varied and flexible PD approaches for digital education can accommodate the diverse needs and preferences of faculty. As such, research to explore which approaches are most effective in different situations may be worthwhile.

\section{Multi-Level Cultural Changes are Needed to Ensure Digital Education Meets Everyone's Expectations}

Given the obstacles to academics' participation in PD and evidence that few faculty members pursue voluntary continuing professional education related to their teaching role (Bates, 2019b; Inamorato dos Santos et al., 2019), cultural change at multiple levels may be warranted. For example, mandatory pre-service PD for faculty or training focused on digital learning for administrators will require substantial cultural shifts. This is especially true in cases where faculty equate learning and growth as learning about and improving their research as opposed to learning about and improving their teaching (Haras, 2018). Such shifts call for administrative leadership through policies and protocols and in-depth consultation to amend hiring, tenure, and promotion processes. Attention to faculty working at the grassroots of the online and digital education community is also important as they push us to those 
liminal spaces where innovation in faculty PD flourishes (Inamorato dos Santos et al., 2019). Making pedagogical training a requirement for academic positions or requiring evidence of in-service training as part of tenure and promotion criteria could stimulate change (Ödalen et al., 2019). In promoting high quality digital education, HEIs should look for ways to foster a culture where faculty embrace pedagogical PD and knowledgeable administration invests in PD and support. The development and implementation of well-articulated strategic plans that identify expectations associated with a range of instructional modalities is another strategy that can be employed by HEIs to further shift this cultural change (e.g., Sharpe et al., 2006).

Immediate actions that HEIs can take in the current environment where contract academic staff make up a substantial proportion of instructors in postsecondary education include ensuring that they are provided with appropriate orientation, on-boarding for digital education, and on-going PD in ways that do not jeopardize their precarious work security. HEIs can also take steps to assess, analyze, and evaluate professional development offerings, especially if pedagogical knowledge and skills are ascribed greater importance in hiring, tenure, and promotion decision-making (Ödalen et al., 2019).

\section{Emergent Needs for Faculty PD}

Due to the impact of COVID-19 on higher education, PD for digital education has become more pressing as most faculty are employing digital learning tools for their instruction. Issues facing higher education involve three big "how to" questions: a) how to rapidly pivot courses from face-to-face to online instruction; b) how to scale digital education options that are effective and engaging for students; and c) how to use evidence-informed practices to guide online learning designs which pay close attention to pedagogy, OER, and equity (Veletsianos, 2020a). Many digital education scholars shared resources and commentary during the 2020 pivot to alternative delivery in higher education (e.g., Imad, 2020; Moore \& Hodges, 2002; Pacansky-Brock, 2020; Veletsianos, 2020b). Webinars and websites related to digital education offered through professional associations also emerged (e.g., Chemical Institute of Canada - Chemistry Education Division, n.d.; Mintz, 2020; National Council on Family Relations, 2020). Understanding how institutions on-boarded faculty during the 2020 pivot to online teaching and varied institutional experiences and best practices in mobilizing the diversity of PD offerings can help institutions respond to future shifts and continue to meet expectations for high quality digital learning.

Challenges around unclear institutional standards for digital education may be straightforward to address through digital education strategies, which are important mechanisms to communicate expectations (Carter et al., 2014). Implementation of these plans will be crucial, given that many Canadian HEIs do not have a fully implemented digital education plan (Johnson, 2019). The profound changes to the higher education landscape in 2020 will impact institutions' investments for faculty PD, training, and support. Further research to investigate ways their aspirations and hopes around professional development investments to build digital education capacity is needed.

Future research in this area may address many gaps. One area noted in this study relates to the recognition that HEI leaders need to have a solid understanding of digital education in order to make informed decisions about faculty PD. Questions about digital education training for administrators could 
be addressed in future research. In describing faculty PD, no respondents shared comments about assessing the effectiveness of their PD offerings. In fairness, this question was not specifically asked by the CDLRA surveys, so we cannot draw the conclusion that HEIs do not evaluate the impacts of these training. However, this is a gap that HEIs should address to both understand whether, and how, institutions evaluate their PD offerings, and the extent to which those are deemed to be effective. Furthermore, institutions mentioned some external PD sources accessed by faculty; however, none mentioned social media and personal learning networks as sites of professional development. These turned out to be rich means through which faculty accessed resources and support during the 2020 pivot to remote teaching, which raises the question: how do these online learning networks fit into the PD landscape?

\section{Limitations}

As a study of PD provided by institutions for digital education, the data used here only presents the perspective of administrators at HEIs; considerations from tenured, tenure-track, sessional, and adjunct faculty members or graduate students are not part of the study. While we chose to use a broad definition of digital education that encompasses all uses of educational technology, respondents may have had a different or narrower definition of digital education. Training needs for faculty at different types of HEIs may differ, but the de-identified data used for this study does not identify the type of institution, precluding such analyses. Not knowing whether a comment was from a college, university, CEGEP, or private college limited our ability to investigate whether findings differed based on type or size of institution, programs offered, or geographic region.

\section{Conclusion}

The 2020 pivot to remote education in response to COVID-19 may serve as an opportunity for strategic change to PD approaches for digital education. This pivot demonstrated the urgent need for ongoing PD for digital education for staff, faculty, and administrators. The findings reported here, therefore, are important and timely, as professional development needs are not only urgent, but ongoing. Preparing faculty to teach and mentor students requires not just familiarity with technology, but familiarity with emergent pedagogical practices, some of which-such as trauma-informed pedagogy-have gained increasing attention during the pandemic. The findings reported here can inform efforts by colleges and universities to address ongoing and emergent needs related to faculty training to ensure excellence, equity, and success in digital education efforts.

\section{Acknowledgements:}

The authors wish to thank and acknowledge the support of the CDLRA team in conducting this research study. This paper draws on research supported by the Social Sciences and Humanities Research Council. 


\section{References}

Austin, A. E., \& Sorcinelli, M. D. (2013). The future of faculty development: Where are we going? New Directions for Teaching and Learning, 133, 85-97. doi:10.1002/t1.20048

Bates, T. (2016, July 6). Getting faculty and instructors into online learning. Online Learning and Distance Education Resources. Retrieved from https://www.tonybates.ca/2016/07/13/gettingfaculty-and-instructors-into-online-learning/

Bates, T. (2019a, May 30). The coming crisis in Canadian postsecondary education: 3 - Some strategies for survival. Online Learning and Distance Education Resources. Retrieved from https://www.tonybates.ca/2019/05/30/the-coming-crisis-in-canadian-postsecondary-education-3some-strategies-for-survival/

Bates, T. (2019b, November 14). Should all lecturers have to have a teaching certificate? Why the answer is a resounding 'yes'. Online Learning and Distance Education Resources. Retrieved from https://www.tonybates.ca/2019/11/14/should-all-lecturers-have-to-have-a-teaching-certificatewhy-the-answer-is-a-resounding-yes/

Bates, T., Desbiens, B., Donovan, T., Martel, E., Mayer, D., Paul, R., Poulin, R., \& Seaman, J. (2017). Tracking online and distance education in Canadian universities and colleges: 2017. Canadian National Survey of Online and Distance Education in Canadian Post Secondary Education. Canadian Digital Learning Research Association. Vancouver, Canada. Retrieved December 18, 2019 from https://onlinelearningsurveycanada.ca/publications-2017/

BCcampus. (n.d.). SCoPE - BCcampus Learning + Teaching. BCcampus. https://scope.bccampus.ca/course/index.php?categoryid $=16$

Brown, M., McCormack, M., Reeves, J., Brooks, D.C., \& Grajek, S. with Alexander, B., Bali, M., Bulger, S., Dark, S., Engelbert, N., Gannon, K., Gauthier, A., Gibson, D., Gibson, R., Lundin, B., Veletsianos, G., \& Weber, N. (2020). 2020 EDUCAUSE Horizon Report, Teaching and Learning Edition. Louisville. https://library.educause.edu//media/files/library/2020/3/2020_horizon_report_pdf.pdf?la=en\&hash=08A92C17998E8113BCB1 5DCA7BA1F467F303BA80

Carter, L. M., \& Brockerhoff-Macdonald, B. (2011). The continuing education of faculty as teachers at a mid-sized Ontario aniversity. The Canadian Journal for the Scholarship of Teaching and Learning, 2(1). doi:10.5206/cjsotl-rcacea.2011.1.4

Carter, L. M., Salyers, V., Myers, S., Hipfner, C., Hoffart, C., MacLean, C., White, K., Matus, T., Forssman, V., \& Barrett, P. (2014). Qualitative insights from a Canadian multi-institutional research study: In search of meaningful e-learning. The Canadian Journal for the Scholarship of Teaching and Learning, 5(1). doi:10.5206/cjsotl-rcacea.2014.1.10

Charmaz, K. (2006). Constructing grounded theory: A practical guide through qualitative analysis. London: Sage Publications. 
Chemical Institute of Canada - Chemistry Education Division. (n.d.) Chemistry online. Retrieved from http://chemedcanada.com/online

Christensen Hughes, J., \& Mighty, J. (2010). Taking stock: Research on teaching and learning in higher education. Montreal and Kingston: McGill University and Queen's University Press.

Cooney, R. (2019, October 17). Conscious onboarding: 10 ways to support new online instructors. Evollution. Retrieved from https://evolllution.com/programming/teaching-and-learning/consciousonboarding-10-ways-to-support-new-online-instructors/

Creswell, J. W. (2014). Research design: Qualitative, quantitative and mixed methods approaches (4th ed.). Lincoln: Sage Publications.

Darling-Hammond, L. (2017). Effective teacher professional development. Palo Alto, CA: Learning Policy Institute.

Donovan, T., Bates, T., Seaman, J., Mayer, D., Martel, E., Paul, R., Desbiens, B., Forssman, V., \& Poulin, R. (2018). Tracking online and distance education in Canadian universities and colleges: 2018. Canadian National Survey of Online and Distance Education in Canadian Post Secondary Education. Canadian Digital Learning Research Association. Vancouver, Canada. Retrieved December 18, 2019 from https://onlinelearningsurveycanada.ca/publications-2018/

@eCampus Ontario. (n.d.). FLO Facilitation Guide: Facilitating Learning Online. Retrieved from https://openlibrary.ecampusontario.ca/catalogue/item/?id=a5558817-273d-4798-b64b$\underline{91 \mathrm{~b} 443789 \mathrm{c} 17}$

Freeman, M., deMarrais, K., Preissle, J., Roulston, K., \& St. Pierre, E. A. (2007). Standards of evidence in qualitative research: An incitement to discourse. Educational Researcher, 36(1), 25-32. doi:10.3102/0013189X06298009

Glaser, B. G., \& Strauss. A. (1967). The discovery of grounded theory: Strategies for qualitative research. Chicago, IL: Aldine Publishing Co.

Gregory, J., \& Cusson, M. (2013). The role of new faculty orientations in improving the effectiveness of postsecondary teaching - Part 2: College sector. Toronto: Higher Education Quality Council of Ontario. Retrieved from http://www.heqco.ca/SiteCollectionDocuments/NFO2 ENG.pdf

Haras, C. (2018, January 17). Faculty development as an authentic professional practice. Higher Education Today. https:/www.higheredtoday.org/2018/01/17/faculty-development-authenticprofessional-practice/

Hénard, F. (2009). Learning our lesson: review of quality teaching in higher education. OECD Publishing. https://www.oecd.org/education/imhe/learningourlessonreviewofqualityteachinginhighereducation. htm 
Hénard, F., \& Roseveare, D. (2012) Fostering quality teaching in higher education: Policies and practices. OECD Publishing. https://www.oecd.org/education/imhe/QT\%20policies\%20and\%20practices.pdf

Imad, M. (2020, March 17). Hope matters. Inside Higher Ed. https://insidehighered.com/advice/2020/03/17/10-strategies-support-students-and-help-them-learnduring-coronavirus-crisis\#.XnKTPyxnlVM.twitter

Inamorato dos Santos, A., Gaušas, S., Mackevičiūtè, R., Jotautytė, A., \& Martinaitis, Ž. (2019). Innovating professional development in higher education: Case studies. Publications Office of the European Union. doi:10.2760/26224

Johnson, N. (2019). Tracking online education in Canadian universities and colleges: National survey of online and digital learning (2019 National Report). Canadian Digital Learning Research Association. Retrieved from https://onlinelearningsurveycanada.ca/publications-2019/

Johnston, S. (1997). Preparation for the role of teacher as part of induction into faculty life and work. New Directions for Teaching and Learning, 1997(72), 31-39. doi:10.1002/t1.7204

Kneale, P., Winter, J., Turner, R., Spowart, L., Hughes, J., McKenna, C., \& Muneer, R. (2016). Evaluating teaching development in higher education. Towards impact assessment: Literature review. York: Higher Education Academy. https://s3.eu-west-

2.amazonaws.com/assets.creode.advancehe-documentmanager/documents/hea/private/evaluating teaching development in he literature review1 1 1568037347.pdf

Miles, C., \& Polovina-Vukovic, D. (2012). The role of new faculty orientations in improving the effectiveness of university teaching - Part 1: University Sector. Toronto: Higher Education Quality Council of Ontario. http://www.heqco.ca/SiteCollectionDocuments/NFO\%20ENG.pdf

Miller, A. A. (1997). ERIC review - Back to the future: Preparing community college faculty for the new millennium. Community College Review, 24(4), 83-92. doi:10.1177/009155219702400406

Mintz, S. (2020, March 17). Transitioning to online teaching: A how-to guide. Perspectives on History. https://www.historians.org/publications-and-directories/perspectives-on-history/march2020/transitioning-to-online-teaching-a-how-to-guide

Moore, S., \& Hodges, C. B. (2020, March 11). So you want to temporarily teach online. Inside Higher Ed. https://www.insidehighered.com/advice/2020/03/11/practical-advice-instructors-faced-abruptmove-online-teaching-opinion

National Council on Family Relations. (2020, April 1). New NCFR resources to help faculty move classes online. https://www.ncfr.org/news/resources-about-novel-coronavirus-covid-19\#move 
Ödalen, J., Brommesson, D., Erlingsson, G. Ó., Schaffer, J. K., \& Fogelgren, M. (2019). Teaching university teachers to become better teachers: The effects of pedagogical training courses at six Swedish universities. Higher Education Research \& Development,38(2), 339-353. doi:10.1080/07294360.2018.1512955

Pacansky-Brock, M. (2020). Humanizing temporary remote teaching and learning [Google Slides]. https://docs.google.com/presentation/d/1PT6gdpVrDCDssCuODjaLQMLj9NTPyeWqURqaJX1BVc/edit\#slide=id.p

Patton, M. Q. (2015). Qualitative research and evaluation methods (4th ed.). Thousand Oaks, CA: Sage.

Pettigrew, T. (2011, November 7). Why profs don't need more teacher training. Maclean's. https://www.macleans.ca/education/uniandcollege/why-profs-dont-need-more-teacher-training/

Randall, N., Heaslip, P., \& Morrison, D. (2013). Campus-based educational development \& professional learning: Dimensions \& directions. Vancouver, BC, Canada: BCcampus. https://scope.bccampus.ca/course/view.php?id=379

Rodgers, R., Christie, J., \& Wideman, M. (2014). The effects of a required faculty development program on novice faculty self-efficacy and teaching. Toronto: Higher Education Quality Council of Ontario.

http://www.heqco.ca/SiteCollectionDocuments/Durham\%20Required\%20Faculty\%20Dev\%20EN G.pdf

Sandelowski, M. (2000). Focus on research methods. Whatever happened to qualitative description? Research in Nursing and Health, 23, 334-340. doi:10.1002/1098-240X(200008)23:4<334::AIDNUR9>3.0.CO;2-G

Sharpe, R., Benfield, G., \& Francis, R. (2006). Implementing a university e-learning strategy: Levers for change within academic schools. ALT-J, Research in Learning Technology, 14(2), 135-151. doi:10.1080/09687760600668503

Sorcinelli, M. D., Austin, A. E., Eddy, P., \& Beach. A. (2006). Creating the future of faculty development: Learning from the past, understanding the present. Anker Press.

Veletsianos, G. (2020a). Canadian higher education. In M. Brown, M. McCormack, J. Reeves, D. C. Brooks, \& S. Grajek (Eds.), 2020 EDUCAUSE Horizon Report, Teaching and Learning Edition. EDUCAUSE (pp. 40-41). https://library.educause.edu//media/files/library/2020/3/2020horizonreport.pdf?la=en\&hash=DE6D8A3EA38054FDEB33C8E 28A5588EBB913270C

Veletsianos, G. (2020b, April 7). A pan-Canadian effort in online education? PD not content. George Veletsianos, PhD. https:/www.veletsianos.com/2020/04/07/a-canadian-national-effort-in-onlineeducation-pd-not-content/ 
Veletsianos, G., VanLeeuwen, C.A., Belikov, O., \& Johnson, N. (2020). Digital education in Canadian postsecondary education: Qualitative analysis of open-ended questions from national surveys 2017-2019. Manuscript submitted for publication.

Wells, E., Roberts, T., \& Riddell, J. (2019, October 19). The Maple League teaching and learning project [Conference session]. Atlantic Universities' Teaching Showcase, Charlottetown, PE, Canada. 


\section{Authors}

Charlene A. VanLeeuwen is a postdoctoral researcher at Royal Roads University and an instructor at the University of Prince Edward Island. Charlene has expertise in qualitative interpretive research methods and employs a broad range of digital education technologies and approaches in her teaching practice. Her research interests revolve around digital and community-based learning, international development work in rural Kenya and faculty development. https://orcid.org/0000-0002-8603-1320

Email: charlene.vanleeuwen@royalroads.ca; cvanleeuwen@upei.ca

George Veletsianos is the Canada Research Chair in Innovative Learning and Technology and the Commonwealth of Learning Chair in Flexible Learning at Royal Roads University. George's research aims to understand and improve teaching, learning, and participation in digital learning environments. His research interests center around learners' and faculty experiences surrounding online learning, flexible learning, networked scholarship, open education, and emerging technopedagogical practices. https://orcid.org/0000-0002-6579-9576

Email: george.veletsianos@,royalroads.ca

Olga Belikov is a learning technologist at Simon Fraser University. She has a background as an instructional designer and educational researcher. Olga is also part of the research team at Royal Roads University which is exploring the nature of academics' online participation over time. Her research interests include networked technologies, online participation, open education, open scholarship, and emerging learning technologies. https://orcid.org/0000-0001-5016-1927

Email: olgambelikov@gmail.com

Nicole Johnson is the Research Director of the Canadian Digital Learning Research Association and was the primary author for the 2019 CDLRA National Report. Nicole is an online PhD student in the Education and ICT (e-learning) program at the Open University of Catalonia in Barcelona, Spain. She is also part of this research team at Royal Roads University. https://orcid.org/0000-0002-3364-4908

Email: digitalnicole78@gmail.com

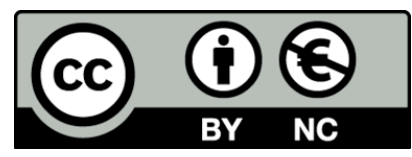

This work is licensed under a Creative Commons Attribution-NonCommercial CCBY-NC 4.0 International license. 